\title{
Descrição de uma nova espécie de Cordiluroides Albuquerque (Diptera, Muscidae, Coenosiinae)
}

\author{
Márcia Souto Couri ${ }^{1,2}$ \\ Debora Gonçalves ${ }^{1,3}$
}

\begin{abstract}
Description of a new species of Cordiluroides Albuquerque (Diptera, Muscidae, Coenosiinae). Cordiluroides paulistensis sp. nov. from Salesopolis, São Paulo, Brazil is described and illustrated.
\end{abstract}

KeYwords. Cordiluroides paulistensis; Diptera; Muscidae; taxonomy.

\section{INTRODUÇÃO}

Albuquerque (1954) propôs Cordiluroides, gênero pertencente à subfamília Coenosiinae, para incluir três espécies descritas no mesmo trabalho: Cordiluroides listrata, Cordiluroides megalopyga e Cordiluroides neotropica. PonT (1972) propôs duas novas combinações para o gênero: Cordiluroides bicolor (Bigot, 1885) e Cordiluroides insularis (Williston, 1896).

LOPES \& COURI (1989) mencionaram a possibilidade de Cordylura geniculata Macquart, 1851 também pertencer a este gênero, com base em comentário de A. C. Pont (University Museum of Natural History, Oxford) que examinou o holótipo desta espécie.

COURi \& PAmplona (1992) posicionaram Cordiluroides entre os Coenosiini (Coenosiinae), utilizando a metodologia de CARvalho (1989); apresentaram uma redescrição do gênero, com transferência de Cordylura geniculata para Cordiluroides, e propuseram Cordiluroides neotropica como sinônimo de Cordiluroides listrata. Uma chave para identificação das cinco espécies incluídas (C. bicolor, $C$. geniculata, C. insularis, C. listrata e C. megalopyga) foi apresentada. Na diagnose de C. insularis, os autores mencionaram erroneamente a posição da antena inserida bem abaixo da metade dos olhos quando, na verdade, é inserida bem acima, de acordo com a diagnose genérica (Albuquerque, 1954).

CARVAlHo et al. (1993) catalogaram cinco espécies válidas para Cordiluroides: C. bicolor, C. geniculata, C. insularis, $C$. listrata e C. megalopyga.
Couri \& PONT (1999) apresentaram uma chave para os gêneros de Coenosiini onde Cordiluroides foi posicionado próximo a Neodexiopsis Malloch, 1920. Os dois gêneros são segregados pela posição da inserção das antenas, número de cerdas intralares e formato da caliptra inferior.

COURI \& PONT (2000) propuseram uma classificação para os gêneros de Coenosiini do mundo, com base na metodologia cladística, onde Cordiluroides aparece em tricotomia com Haroldopsis Albuquerque,1954 e Neodexiopsis, reunidos pela presença de três cerdas pré apicais na face dorsal do fêmur posterior.

Neste trabalho uma nova espécie de Cordiluroides, $C$. paulistensis sp. nov. é descrita.

\section{MATERIALE MÉTODOS}

O material estudado está depositado no Canadian National Collection of Insects, Ottawa, Canadá (CNC), e no Museu Nacional, Rio de Janeiro, Brasil (MNRJ).

Para dissecção do ovipositor, o abdome foi destacado do corpo e colocado em solução de hidróxido de potássio a $10 \%$, a frio, por 24 horas. Após esse período, passou por uma série alcoólica, sendo finalmente dissecado em glicerina. Após o estudo e confecção das ilustrações, o material foi acondicionado em tubinho com glicerina e fixado com alfinete ao lado do exemplar.

\section{Cordiluroides paulistensis sp. nov.}

(Figs. 1-4)

\footnotetext{
1. Departamento de Entomologia, Museu Nacional, Universidade Federal do Rio de Janeiro. Quinta da Boa Vista, São Cristóvão, 20940-040, Rio de Janeiro - RJ, Brasil.

2. Bolsista Produtividade Científica, CNPq. Endereço eletrônico: mcouri@attglobal.net

3. Apoio Técnico, CNPq. Endereço eletrônico: deb@mn.ufrj.br
} 

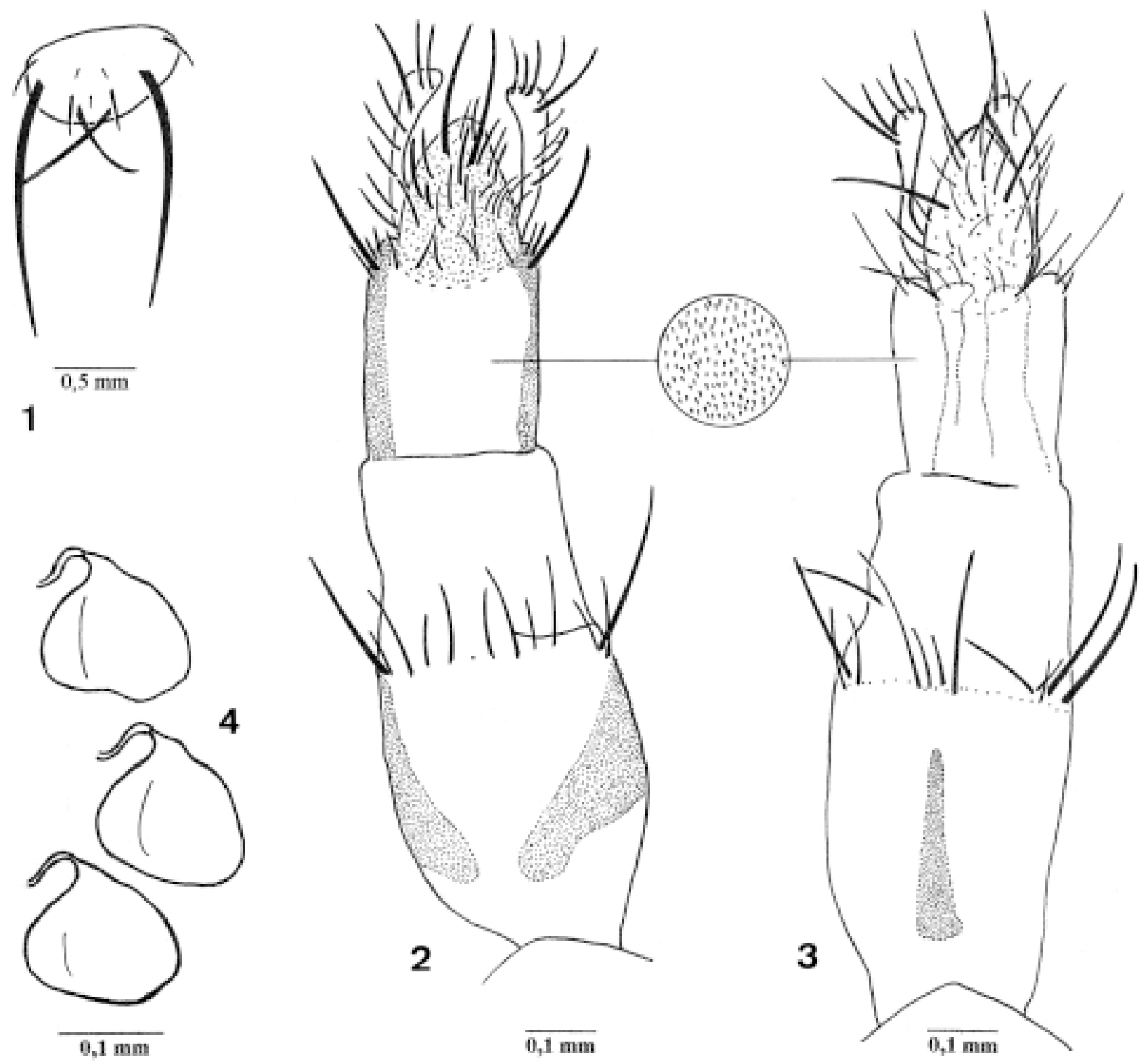

Figs. 1-4. Cordiluroides paulistensis sp. nov. 1, Escutelo; 2, Ovipositor, face dorsal; 3, Ovipositor, face ventral; 4, Espermatecas.

Holótipo: fêmea, etiquetado: Est. Biol. Boracéia. Salesópolis. São Paulo. 14-19. X. 1970 / J. W. Boyes \& J. H. Guimarães "Holotipo" [etiqueta vermelha com linha preta no bordo] (CNC). Exemplar sem perna média direita e sem perna posterior esquerda. Abdome dissecado, acondicionado em tubinho com glicerina.

Parátipo: fêmea com procedência idêntica à do holótipo, "Paratypo" [etiqueta verde com linha preta no bordo] (MNRJ). Exemplar sem pernas anterior e posterior esquerdas.

Diagnose. Coloração geral castanha. Cerdas ocelares presentes e bem finas. Quatro pares de cerdas frontais. Palpo castanho-escuro, mais claro na base. Arista com cílios curtos em toda extensão. Cílios acrosticais em série única. Escutelo com quetotaxia, como na Fig. 1. Asas levemente acastanhadas.
Coloração. Coloração geral castanha. Placa fronto-orbital castanho-escura. Parafaciália e gena prateadas. Triângulo ocelar castanho-escuro. Antena castanho-escura com polinosidade cinza. Arista e palpo castanho-escuros, o último com base mais clara. Mesonoto castanho. Pleuras cinza. Caliptras e balancim amarelo-claros. Asas levemente acastanhadas. Coxa amarelo-clara. Fêmures amarelos: fêmur anterior castanho na face dorsal, femures médio e posterior castanhos no terço apical. Tíbia e tarso castanhos. Unhas negras. Abdome castanho- escuro com áreas polinosas prateadas látero-basais em cada tergito.

Fêmea. 5,0-6,2 mm, asa: 5,6-5,9 mm. 
Cabeça. Olhos afastados, no nível do ocelo anterior, cerca de 0,39 vezes da largura da cabeça. Quatro pares de cerdas frontais, o segundo par curto e fino. Um par de cerdas pósverticais convergentes. Um par de cerdas ocelares, finas, curtas e convergentes. Um par pós- ocelar divergente. Antenas inseridas acima da metade dos olhos. Flagelômero medindo cerca de três vezes o comprimento do pedicelo. Arista ciliada em toda sua extensão. Vibrissa longa e forte. Gena e parafaciália estreitas.

Tórax. Cúlios acrosticais em série única . Cerdas dorsocentrais 1:3. Duas cerdas pós-pronotais; 1 cerda pósumeral; 1 pré-sutural; 1 intralar posterior; 1 cerda supralar; 2 pós supralares. Notopleura com duas cerdas. Anepisterno com uma fileira de quatro cerdas, a primeira mais curta. Escutelo com um longo par de cerdas sub-basal e um par de cerdas apicais com cerca de um terço do comprimento do anterior (Fig. 1). Três cerdas catepisternais (1:1:1). Fêmur anterior nas faces ântero-dorsal e póstero-ventral com uma fileira de cerdas. Tíbia anterior na face anterior com uma cerda longa mediana; face ântero-dorsal com uma cerda pré apical; face póstero-dorsal com uma cerda apical. Fêmur médio na face anterior com duas cerdas submedianas; face ântero-dorsal com três cerdas espaçadas; face póstero-dorsal com duas cerdas pré-apicais. Tíbia média na face anterior com uma longa cerda mediana; face posterior com uma cerda mediana mais curta; faces ânterodorsal e póstero-dorsal com uma cerda pré-apical; faces póstero-dorsal e ventral com uma cerda apical longa e forte. Fêmur posterior na face ântero-ventral com uma fileira de cerdas; face ântero-dorsal com uma fileira espaçada de cerdas; faces ântero-dorsal, dorsal e póstero-dorsal com uma cerda pré-apical. Tíbia posterior na face anterior com uma longa cerda supramediana; face ântero-ventral com uma cerda submediana; face dorsal com uma cerda no terço apical; face ântero-dorsal com uma cerda pré-apical; face ântero-ventral com uma cerda apical.

Abdome. Cerdas laterais nos tergitos 2-5; um par de cerdas discais nos tergitos 4 e 5 .

Terminália. Ovipositor com microtríquias em toda extensão, nas faces dorsal (Fig. 2) e ventral (Fig. 3). Cercos mais longos que o epiprocto e um pouco maiores que o hipoprocto. Epiprocto e hipoprocto com 2 cerdas pré-apicais longas. Tergitos em forma de bastão. Esternito 8 com 3 cerdas apicais.
Três espermatecas piriformes (Fig. 4).

Macho desconhecido.

Registro geográfico: BRASIL, São Paulo: Salesópolis.

Discussão $C$. paulistensis sp. nov. assemelha-se morfologicamente à $C$. megalopyga pela coloração das pernas e pelo comprimento do flagelômero e à $C$. listrata pela presença de cerdas ocelares. Na chave de Couri \& PAmplona (1992), aproxima-se de $C$. listrata, podendo ser segregada pela coloração das pernas

Agradecimentos. Ao Prof. Carlos Einicker Lamas (Museu Nacional, Rio de Janeiro, Pesquisador Associado) pela análise crítica do manuscrito, à Bianca Marques (Museu Nacional, Rio de Janeiro, Bolsista FAPERJ) pela colaboração durante a elaboração deste trabalho e à FAPERJ (proc. E-26/ 171.124/00) pelo suporte financeiro.

\section{REFERÊNCIAS}

Albuquerque, D. DE O.1954. Fauna do Distrito Federal. XXI: Um gênero e três espécies novas de "Coenosiinae" (Diptera, Muscidae). Revista Brasileira de Biologia 14 (4): 361-369.

Carvalho, C. J. B. DE. 1989. Classificação de Muscidae (Diptera): Uma proposta através da análise cladística. Revista Brasileira de Zoologia 6 (4): 627-648.

Carvalho, C. J. B. de; A.C. Pont; M. S. Couri \& D. Pamplona. 1993. MuscidAe. In: Carvalho, C. J. B. (ed). A catalogue of the Fanniidae and Muscidae (Diptera) of the Neotropical Region. Part II. Sociedade Brasileira de Entomologia, São Paulo, 201p.

Couri, M. S. \& D. Pamplona. 1992. Cordiluroides Albuquerque, 1954 (Diptera, Muscidae, Coenosiinae): Redescrições, notas, sinonímia e chave para as espécies. Revista Brasileira de Entomologia 36 (2): 255-262.

Couri, M.S. \& A.C. Pont. 1999. A key to the world genera of the Coenosiini (Diptera, Muscidae, Coenosiinae). Studia dipterologica 6 (1):93-102.

Couri, M.S. \& A.C. Pont. 2000. Cladistic analysis of Coenosiini (Diptera: Muscidae: Coenosiinae). Systematic Entomology 25:373-392.

Lopes, S. M. \& M. S. CouRI. 1989. Notas nomenclaturais sobre Tetramerinx Berg,1989 e redescrição de Tetramerinx unica (Stein), 1898 (Diptera, Muscidae). Boletim do Museu Nacional, N. S., Zoologia 333: 110.

Pont, A. C. 1972. Family Muscidae, (97), p.1-11. In: N. Papavero (ed.) A catalogue of the Diptera of the Americas South of United States. São Paulo, Museu de Zoologia da Universidade de São Paulo. 